\title{
Bemiddeling-mediation: (ontwerp)regelgeving in België, Nederland en de EU met een impressie van de TMD-congresmiddag op 1 december 2016
}

\author{
Rob Jagtenberg \& Annie de Roo
}

Voor u ligt TMD 2016, nr. 4, een bijzondere aflevering die grotendeels gewijd is aan de TMD-congresmiddag die op 1 december 2016 werd gehouden bij partneruitgever Intersentia te Antwerpen-Mortsel. De vergevorderde plannen voor (nieuwe) regelgeving die momenteel in Brussel en in Den Haag ter tafel liggen, vormden de directe aanleiding voor deze goed bezochte middag.

Wat de Belgische plannen betreft, was het Minister van Justitie Koen Geens die zelf enkele tippen van de sluier oplichtte. De Nederlandse plannen werden toegelicht door de heer Dennis Hesemans, Raadadviseur bij het Ministerie van Veiligheid en Justitie, die de Nederlandse minister verving. Bij al deze plannen werd ook het EU-perspectief geenszins uit het oog verloren: mevrouw Karen Vandekerckhove, Gedeputeerd afdelingshoofd bij het EC Directoraat-Generaal Justitie en Consumenten, lichtte de onlangs gepubliceerde resultaten toe van de evaluatie van de EU Mediationrichtlijn uit 2008. TMD prijst zich gelukkig dat de zojuist genoemde sprekers niet alleen het woord wilden voeren op de Congresmiddag, maar ook bereid waren de teksten van hun voordracht aan te leveren voor publicatie in deze speciale aflevering van TMD. De redactie verwacht hiermee niet alleen de aanwezige deelnemers die de voordrachten nog eens willen teruglezen een dienst te bewijzen, maar ook de talrijke belangstellenden die zich wegens het beperkte aantal plaatsen niet meer konden inschrijven; op deze wijze kunnen ook zij de middag alsnog op afstand volgen. Met de genoemde bijdragen van Minister Geens ('Het toekomstig wettelijk kader van bemiddeling in België'), Raadadviseur Hesemans ('Naar een Wet Bevordering Mediation in Nederland') en Directeur Vandekerckhove ('Bemiddeling in Burgerlijke en Handelszaken - de Evaluatie van Richtlijn 2008/52') opent deze aflevering. Een korte impressie van het verdere verloop van de middag - in woord en beeld - volgt hierna, maar niet nadat eerst de verdere bijdragen in deze aflevering kort zijn geïntroduceerd.

\section{Verder in dit nummer}

Het TMD-interview vond ditmaal plaats met Diana Evers, pionier op het terrein van de familiale bemiddeling. Directe aanleiding voor dit interview, afgenomen door Eric Lancksweerdt, vormde de recente verschijning van Diana Evers' boek 'Bemiddeling. Meer dan een Hype' (Acco, 2016). Dat deze titel de huidige situatie goed weergeeft, wordt bevestigd door de drie congresbijdragen, maar bovendien 
ook door de drie signalementen in deze aflevering. Zo wordt op initiatief vanuit het Nederlandse parlement een herinvoering van de Vrederechter met overwegend conciliërende taak in studie genomen; hierover bericht Emese von Bóné ('De Herinvoering van de Vrederechter in Nederland nu toch een Feit?'). Ook de veelheid van studiedagen en congressen - naast die van dit tijdschrift op 1 december 2016 - is indicatief voor de levendige en voortdurende belangstelling voor bemiddeling-mediation: van de diverse initiatieven wordt er in het volgende signalement één nader uitgelicht, te weten de studienamiddag 'Gerechtelijke bemiddeling' aan de Universiteit Hasselt op 15 december 2016, door Eric Lancksweerdt als trait d'union tussen TMD en de UHasselt. Het is de bedoeling dat deze, eveneens succesvolle studienamiddag, in 2017 een vervolgeditie gaat krijgen te Gent. Ook in Nederland vonden de afgelopen periode belangrijke congressen plaats: op 17 november 2016 het jaarlijkse MfN mediationcongres, met als thema 'Bruggen slaan!'. En daarvóór nog, op 27 oktober, het door de Nederlandse Mediators Vereniging NMv georganiseerde congres 'Succesvolle Wetgeving: to opt in or to opt out?!', eveneens over de wetgevingsplannen (en dan vooral de Nederlandse). Voor deze evenementen moeten wij nu volstaan met verwijzing naar de websites van de genoemde organisaties. Het derde en laatste signalement in deze TMD-aflevering betreft de aangekondigde samenwerking tussen de toonaangevende Belgische aanbieders van zakelijke arbitrage respectievelijk bemiddeling, CEPANI en bMediation, waartoe inmiddels een samenwerkingsovereenkomst werd gesloten. Hiermee zijn wij weer op gepaste wijze in de habitus van mediation beland, en daarmee bij de congresmiddag op 1 december 2016.

\section{Impressie TMD-congresmiddag}

De bijeenkomst werd geopend door de hoofdredacteur van TMD Annie de Roo, die benadrukte dat de Nederlands-Vlaamse signatuur van TMD een ideaal platform biedt om elkaar over de grenzen heen te (laten) inspireren. Op het gebied van mediationwetgeving nam België in 2005 al een voorsprong op Nederland, zij het dat de voorstellen in Nederland op dit moment verder uitgekristalliseerd zijn dan de nieuwe Belgische plannen. Daardoor konden alvast - als voorschot op de discussie - enkele saillante reacties worden geparafraseerd van de Nederlandse Orde van Advocaten: Welk probleem zou er nu eigenlijk door deze - onnodige wetgeving opgelost moeten worden? En van de Hoge Raad, het Nederlandse Hof van Cassatie: De rechter kan heel goed zelf mediëren en is veel succesvoller met schikken dan mediators.

De commentaren vanuit de Belgische rechtspraktijk lijken vooralsnog minder vijandig. De positieve stimulansen die de Belgische wetgever lijkt te willen inzetten ter bevordering van bemiddeling klinken veel Nederlandse mediators zelfs als muziek in de oren. Het is inmiddels de vraag in hoeverre cultuurverschillen nu nog een rol spelen tussen onze beide landen als naaste buren. België: 'eerst kaders stellen door regelgeving', versus Nederland: 'eerst gecontroleerd experimenteren'. 
Van de hierop volgende drie voordrachten van Minister Geens, de heer Hesemans en mevrouw Vandekerckhove zijn de (omgewerkte) teksten integraal opgenomen in deze aflevering. Toch enkele saillante losse zinsneden, bij wijze van appetizer.

\section{Minister Geens:}

- 'De Belgische advocatuur heeft de slag om (fiscaalrechtelijke) advieswerkzaamheden gemist en kent daardoor nu een fixatie op de pleitcultuur.'

- 'We zijn eraan gewend dat opname in een hospitaal "niets" kost, omdat we daartegen verzekerd zijn; dat zou met rechtspraak ook zo moeten; ik droom van een algemene verplichte verzekering ook op dit vlak.'

- 'Ik wil naar minder - alleen nog erkende - bemiddelaars, die dan ook ieder een groter volume zaken zullen hebben, en daardoor ook meer bestaanszekerheid.'

De heer Hesemans:

- 'De kritiek op de oorspronkelijke initiatiefwetsvoorstellen Bevordering Mediation van (toen nog) parlementslid Ard van der Steur betrof het te grote aantal vlieguren (praktijkervaring) dat van (aspirant) registermediators werd geëist, een teveel aan tuchtrecht, en bovenal het artikel (het voorziene artikel 22a Burgerlijke Rechtsvordering) waarin bepaald werd wanneer een geschil vermoed moet worden zich te lenen voor rechterlijke doorverwijzing naar mediation. Daarmee heeft (inmiddels ook weer voormalig) Minister Van der Steur in het departementale wetsvoorstel rekening willen houden.'

En mevrouw Vandekerckhove:

- 'Op de Consultatie is vooral gereageerd vanuit Roemenië (20\%), Spanje (17\%), en Frankrijk (16\%), en - in iets minder mate - vanuit Duitsland (9\%).'

- 'Een door de EU zeer gewaardeerd voorbeeld van de wijze waarop mediation in rechtspraak is geïntegreerd, biedt de Nederlandse voorziening bij internationale kinderontvoeringen, waarbij in een zaak die op vrijdag wordt aangebracht, meteen op zaterdag en zondag mediation wordt beproefd en dan op maandag reeds een zitting kan plaatsvinden.'

Maar met deze korte zinsneden doen we zeker geen recht aan de breedte en rijkdom van de presentaties.

Ook ten aanzien van de forumdiscussie die na de pauze plaatsvond, zal het bij enkele losse impressies moeten blijven. Het panel bestond uit mevrouw Veerle Vangheluwe, vicevoorzitter van de Federale Bemiddelingscommissie, de heer Daan de Snoo, secretaris van de Mediatorsfederatie Nederland, en de TMD-redactieleden Herman Verbist en Rob Jagtenberg. De rol van Daan de Snoo werd in het laatste kwartier overgenomen door mediation-pionier en advocaat John Bosnak.

De discussieleiders waren professor Ad Kil, emeritus hoogleraar Nyenrode Business Universiteit, en TMD-redactielid Barbara Gayse, tevens verbonden aan de Federale Bemiddelingscommissie.

De levendige discussie met de zaal concentreerde zich vooral rond de opleiding en kwalificatie-eisen voor bemiddelaars/mediators, en rond de onderlinge verhou- 
ding tussen bemiddelaar-mediator en rechter. Bij dit laatste punt kwam onder meer aan de orde de vraag in hoeverre procespartijen verplicht zouden moeten worden eerst aan een (voorlichtingssessie over) bemiddeling-mediation deel te nemen. Vanuit de MfN wordt het huidige Nederlandse wetsvoorstel in dit opzicht gezien als een stap achteruit ten opzichte van de oorspronkelijke initiatiefwetsvoorstellen ter bevordering van mediation. Het komt voor dat een van de partijen wel genegen is om de weg van bemiddeling te gaan, maar de tegenpartij vasthoudt aan zijn recht op toegang tot de rechter. Een intrigerende stelling (afkomstig van oud-minister Ard van der Steur) luidt, dat in dit soort situaties vrijwilligheid voor de onwillige partij een verplichting voor de welwillende partij (namelijk om zich te onderwerpen aan rechtspraak) impliceert.

Een hiermee verband houdend thema dat aan de orde kwam, was wie nu eigenlijk de meest aangewezene is om een conflictdiagnose op te maken en daarmee te bepalen welke strategie of methode de meest geëigende is: de advocaat, de rechter of de bemiddelaar; of misschien vooreerst de partij zelf.

Een andere kwestie die werd aangesneden, was of de overheid als partij in een conflict niet steeds het goede voorbeeld zou moeten geven door een op erkenning van wederzijdse belangen gerichte conflictbenadering te prioriteren.

Het thema 'opleiding en kwalificatie-eisen' zorgde eveneens voor veel discussie onder de aanwezigen. Opvallende verschillen tussen België en Nederland kwamen naar voren ten aanzien van de huidige programma's van de opleidings- en vormingsinstituten. Die verschillen betroffen zowel de omvang in uren, als de onderlinge verhouding tussen theoretische basisvorming en praktijkgerichte training. Ook de wijze van kwaliteitsborging voor bemiddelaars-mediators in vergelijking met aangrenzende professies (psychotherapeut, schade-expert) kwam uitgebreid aan bod.

Een gesignaleerde complicatie betreft de diversiteit aan voorkennis en vooropleidingen van diegenen die zich professioneel willen bekwamen tot bemiddelaarmediator. Toepasselijk passeerde ook het onderwerp van wederzijdse erkenning van kwalificaties tussen Belgische bemiddelaars en Nederlandse mediators de revue; een dergelijke erkenning zou gewaarborgd zijn wanneer de beroepskwalificatie als hogeronderwijsdiploma zou kunnen worden aangemerkt, maar ook dan kunnen, onder het huidige Europese recht, nog aanvullende praktijkeisen over en weer gesteld worden.

Dit was slechts een betrekkelijk willekeurige greep uit de onderwerpen die ter sprake kwamen. Waarschijnlijk zijn er, door de beperkingen in de tijd, nog veel onderwerpen die niet eens ter sprake konden komen, zoals de vraag die de hoofdredacteur aan het begin van de middag terloops opwierp: 'Wordt bemiddeling niet te zeer gereguleerd om andere problemen elders op te lossen (zoals: een overbelaste rechtspraak)?' Maar naar analogie van het advies 'Tijdsbestek op zitting te krap? - dan doorverwijzen naar mediation', dat figureert op het fiche 'Tips bij doorverwijzing op de zitting' dat Nederlandse rechters gebruiken, moeten ook op deze plaats de beperkingen van een congresnamiddag aanvaard worden. Er 
komen ongetwijfeld nog volgende gelegenheden om belangrijke onderwerpen verder uit te diepen.

De congresmiddag werd afgesloten met een speciaal woord van dank aan meester Herman Verbist, die, van alle organisatoren, op zijn eigen, enthousiaste wijze wel het meeste werk achter de schermen heeft verzet voor dit alleszins geslaagde congres.

\section{TMD-congresmiddag in Antwerpen-Mortsel}

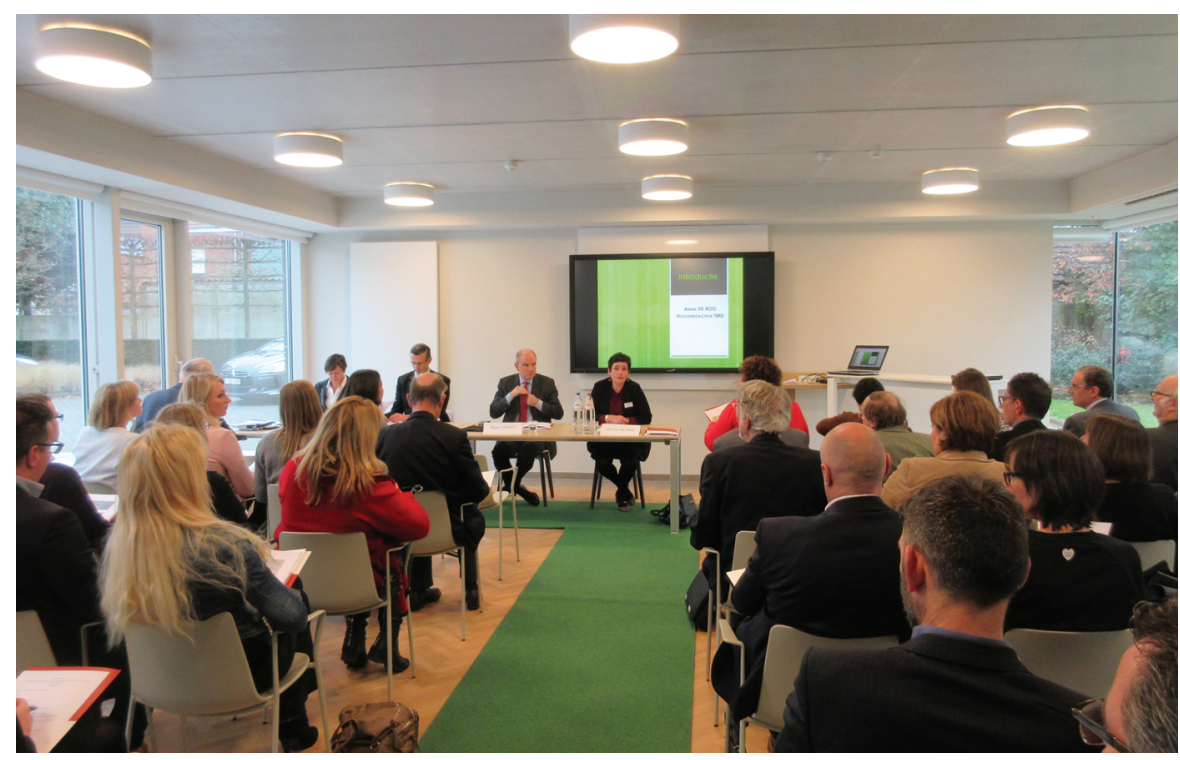

\section{Koen Geens en Annie de Roo}

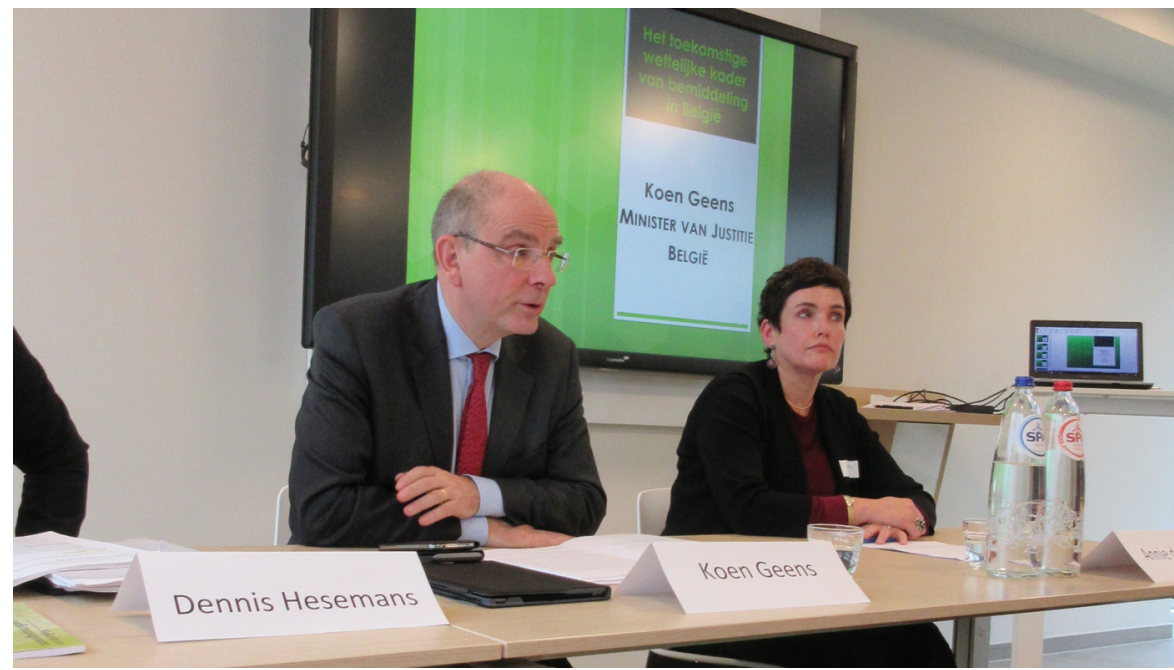




\section{Karen Vandekerckhove, Dennis Hesemans en Annie de Roo}

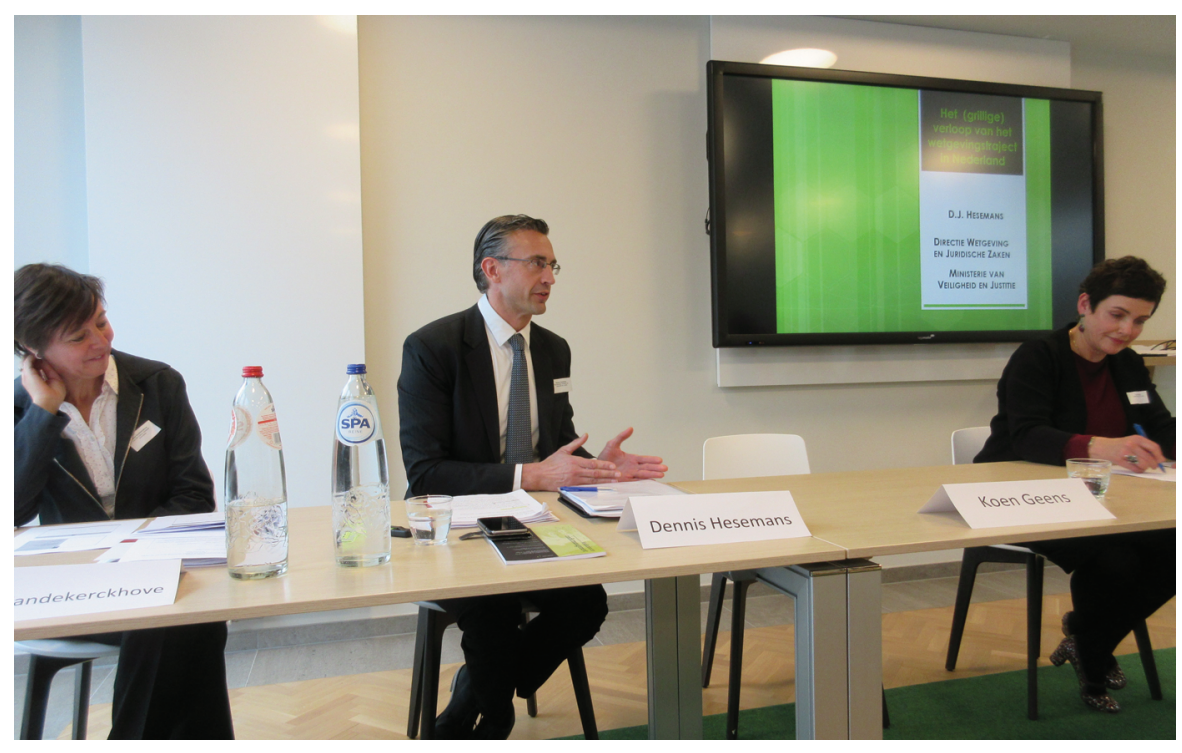

\section{Voordracht Dennis Hesemans}






\section{Discussieleiders Barbara Gayse en Ad Kil}

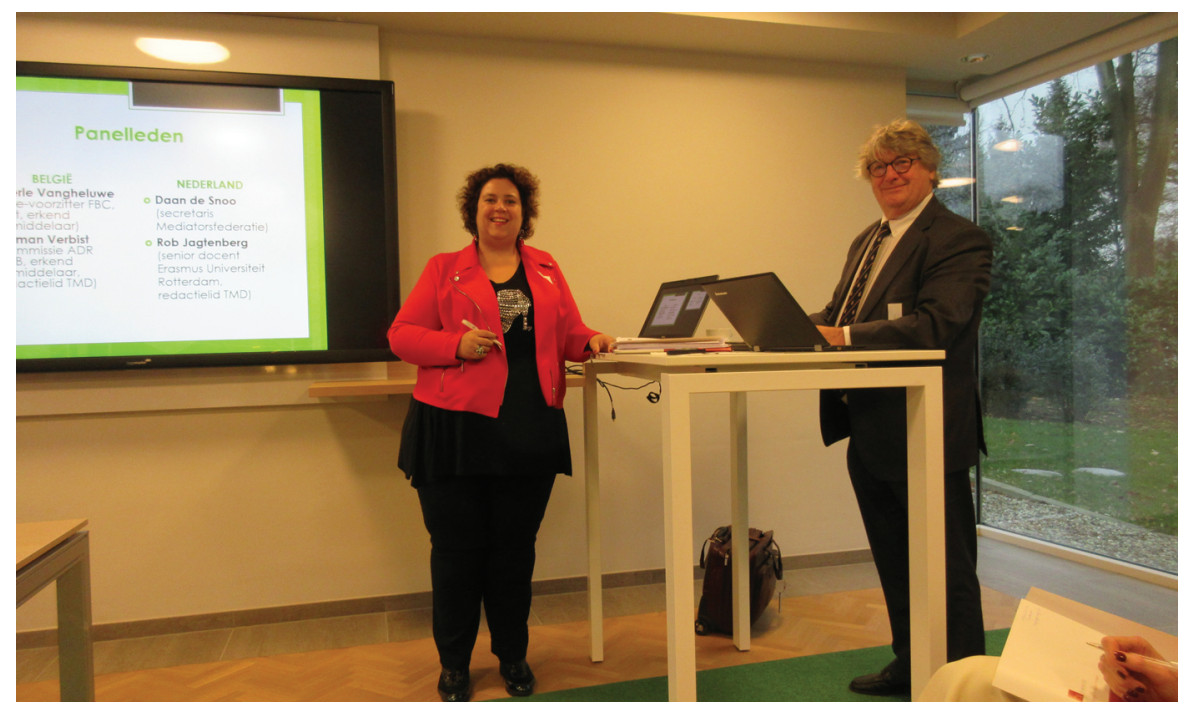

Forumdiscussie met Rob Jagtenberg, Daan de Snoo, Veerle Vangheluwe en Herman Verbist

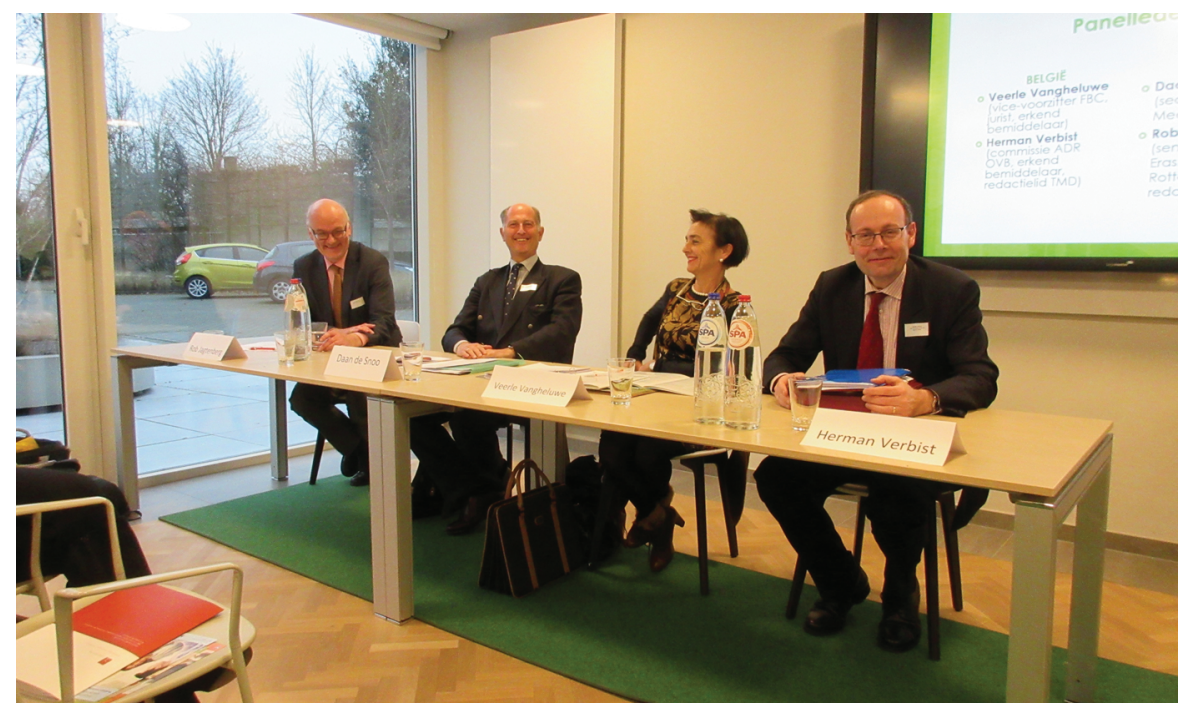

